\title{
Inhibitory Effect of Fentanyl on Phenylephrine-Induced Contraction on Rabbit Aorta
}

\author{
Sevda Sasmaz ${ }^{1}$, Ayse Saide Sahin ${ }^{2}$ Ipek Duman $^{2 *}$ \\ ${ }^{1}$ Departments of Anesthesia and Pharmacology, Selcuk University, Konya, Turkey; Ipek Duman, ${ }^{2}$ Department of Pharmacology, \\ Selcuk University, Meram Faculty of Medicine, Konya, Turkey. \\ Email: *aduman@selcuk.edu.tr
}

Received January $1^{\text {st }}, 2011$; revised April 10 ${ }^{\text {th }}, 2011$; accepted May $4^{\text {th }}, 2011$.

\begin{abstract}
This in vitro study was designed to assess the effects of fentanyl on isolated rabbit thoracic aorta rings contracted with phenylephrine. Methods included contraction of aorta rings with phenylephrine $\left(10^{-5} \mathrm{M}\right)$ and recording the changes after increasing concentrations of fentanyl $\left(10^{-9} \mathrm{M}-10^{-5} \mathrm{M}\right)$. Similar experiments were done after incubation with $N^{\omega}$ nitro-L-arginine methyl ester $\left(10^{-4} \mathrm{M}\right)$, indomethacin $\left(10^{-5} \mathrm{M}\right)$, naloxone $\left(10^{-5} \mathrm{M}\right)$, ouabain $\left(10^{-5} \mathrm{M}\right)$, TEA $\left(10^{-4} \mathrm{M}\right)$ and glibenclamide $\left(10^{-5} \mathrm{M}\right)$. It was revealed that, fentanyl causes relaxation in rabbit aorta rings precontracted with phenylephrine. Removal of endothelium significantly reduces the relaxant response to fentanyl. Nitric oxide synthase inhibitor L-NAME, $\mathrm{K}^{+}$channel blocker glibenclamide and $\mathrm{Na}^{+}-\mathrm{K}^{+}$-ATPase inhibitor ouabain inhibits the relaxant effect of fentanyl in endothelium intact aorta rings. These results suggest that fentanyl causes dose dependent vasodilatation in the rabbit aorta via activation of $K_{A T P}$ channels and $\mathrm{Na}^{+}-\mathrm{K}^{+}$-ATPase, and nitric oxide released from endothelium.
\end{abstract}

Keywords: Fentanyl, Nitric Oxide, Potassium Channels, Rabbit, Vascular Smooth Muscle

\section{Introduction}

Fentanyl is a synthetic opioid which is commonly used for cardiac and vascular anesthesia in very high doses [1, 2]. Opioids can have marked effects upon the circulation in animals, and these effects can be mediated by either alteration in autonomic nervous system activity or by direct actions on blood vessels [1]. Studies regarding the effects of fentanyl on different vascular structures, and the mechanisms involved in these actions revealed conflicting results [3-5]. While some reports claim that fentanyl acts as an alpha-blocker [6], others demonstrated that fentanyl attenuates norepinephrine and epinephrine-mediated contractions independent of opioid receptors and endothelial function [7]. Thus it would appear that different mechanisms might be involved in fentanyl's vascular effects, depending on the species and the blood vessel. To best of our knowledge, the effect of fentanyl on rabbit aorta has not been studied. This in vitro study was designed to assess the effects and the possible mechanisms of these effects of fentanyl on isolated rabbit thoracic aorta rings contracted with phenylephrine.

\section{Materials and Methods}

With approval from our Institutional Animal Care and Use Committee, male New Zealand rabbits $(3-4 \mathrm{~kg}$; Selcuk University Experimental Medicine Research and Application Centre) were anesthetized with ether and were sacrificed by rapid exsanguination.

\subsection{Sample Collection and Blood Vessel Preparation}

The thoracic aorta was removed and placed in warm Krebs-Henseleit Solution (KHS). The excess fat and connective tissue were removed from the vessel and cut into spiral strips $10-15 \mathrm{~mm}$ in length. The strips were suspended between two stainless steel hooks in organ baths $(10 \mathrm{ml})$ containing Krebs-Henseleit buffer maintained at $37^{\circ} \mathrm{C}$. One hook was anchored onto the organ bath and the other was connected to a movable transducer (Model FT 03, Grass Instrument Co. MA, USA) and a polygraph (Model 7, Grass Instrument Co. MA, USA) for measurement and recording of changes in isometric tension. 


\subsection{Experimental Protocol}

Strips were aerated with a gas mixture of $95 \% \mathrm{O}_{2}, 5 \%$ $\mathrm{CO}_{2}$ throughout the experiment. Strips were initially placed under a resting tension of $1.5 \mathrm{~g}$ and were allowed to equilibrate for one hour. During this period the bath solution was changed every 10 minutes and the resting tension was readjusted to the $1.5 \mathrm{~g}$ level.

Some protocols were conducted with endothelium intact artery strips while some protocols were conducted with endothelium denuded artery strips. Endothelium removal was done by gently denuding the endothelium of the aorta with cotton swabs. The integrity of the endothelium were assessed by pre-contracting the rings with phenylephrine $\left(10^{-5} \mathrm{M}\right)$, then adding acetylcholine $\left(10^{-6} \mathrm{M}\right)$ before each experiment. This confirmed removal of a major portion of the endothelium because endothelium-denuded vessels contracted in response to acetylcholine, whereas endothelium intact vessels relaxed.

After an equilibrium period, the following procedures were conducted:

Protocol 1: to assess the effect of the endothelium, effect of cumulative fentanyl on phenylephrine induced contractions in aorta strips with intact endothelium $(n=8)$ and denuded endothelium $(n=8)$ were studied. In aorta strips with and without endothelium, after a resting period, and the maximal contractile response to $10^{-5} \mathrm{M}$ phenylephrine had been recorded, increasing concentrations of fentanyl $\left(10^{-9} \mathrm{M}-10^{-5} \mathrm{M}\right)$ were added cumulatively to the bath and the concentration-response curves were obtained.

Protocol 2: to determine whether the vasorelaxant effect of fentanyl is mediated by nitric oxide (NO) or prostanoids, endothelium intact aorta strips precontracted with phenylephrine $\left(10^{-5} \mathrm{M}\right)$ were incubated for $20 \mathrm{~min}$ utes with a NO synthase inhibitor, $\mathrm{N}^{\omega}$-nitro-L-arginine methyl ester (1-NAME) $\left(10^{-4} \mathrm{M}\right)(\mathrm{n}=8)$ and a cyclooxygenase inhibitor, indomethacin $\left(10^{-5} \mathrm{M}\right)(\mathrm{n}=8)$ After this incubation, concentration-response curves were obtained to cumulative doses of fentanyl $\left(10^{-9} \mathrm{M}-\right.$ $\left.10^{-5} \mathrm{M}\right)$.

Protocol 3: to evaluate the role of opioid receptors in the effect of fentanyl, the endothelium intact aorta strips precontracted with phenylephrine $\left(10^{-5} \mathrm{M}\right)$ were incubated for 20 minutes with naloxone $\left(10^{-5} \mathrm{M}\right)(\mathrm{n}=8)$. After this incubation, concentration-response curves were obtained to cumulative doses of fentanyl $\left(10^{-9} \mathrm{M}-\right.$ $\left.10^{-5} \mathrm{M}\right)$

Protocol 4: to determine whether the vasorelaxant effect of fentanyl is mediated by $\mathrm{K}^{+}$channels, the endothelium intact aorta strips were preincubated with $\mathrm{K}^{+}$channel blockers glibenclamide $\left(10^{-6} \mathrm{M}\right)(\mathrm{n}=8)$ and tetra- ethylammonium (TEA,) $\left(10^{-4} \mathrm{M}\right)(\mathrm{n}=8)$ after maximal contractile response to phenylephrine $\left(10^{-5} \mathrm{M}\right)$, fentanyl $\left(10^{-9}-10^{-5} \mathrm{M}\right)$ was added 20 minutes later, and concentration-response curves were recorded.

Protocol 5: endothelium intact aorta strips precontracted with phenylephrine $\left(10^{-5} \mathrm{M}\right)$ were incubated for $20 \mathrm{~min}$ utes with $\mathrm{Na}^{+}-\mathrm{K}^{+}$-ATPase inhibitor, ouabain $\left(10^{-5} \mathrm{M}\right)(\mathrm{n}$ $=8$ ) before fentanyl $\left(10^{-9}-10^{-5} \mathrm{M}\right)$ was added, and dose-response curves were recorded.

Modified Krebs-Henseleit solution was prepared in the laboratory with compositions of (in $\mathrm{mM}$ ) NaCl 119; KCl 4.7; $\mathrm{MgSO}_{4} 1.5 ; \mathrm{KH}_{2} \mathrm{PO}_{4} 1.2 ; \mathrm{CaCl}_{2} 2.5 ; \mathrm{NaHCO}_{3} 25$; glucose 11. Fentanyl was obtained from Abbott, (Abbott Park, IL, USA) and phenylephrine, $\mathrm{N}^{\omega}$-nitro-L-arginine methyl ester (L-NAME), indomethacin, ouabain, naloxone, glibenclamide and tetraethyl ammonium (TEA); were purchased from Sigma Chemical Co. (St. Louis, MO, USA). All agents were dissolved in distilled water.

\subsection{Data and Statistical Analysis}

The effects of fentanyl are expressed as the percentages of the control contractile response elicited at $10^{-5} \mathrm{M}$ of phenylephrine. $\mathrm{pIC}_{50}$ values (the negative logarithm of concentration eliciting $50 \%$ of the maximal relaxation) and $E_{\max }$ values (the percentage of the maximal response of the tissue) were calculated. Results are expressed as means $\pm S D$. Results were evaluated using Student $t$ test. A $p$ value of $<0.05$ was considered significant.

\section{Results}

Phenylephrine $\left(10^{-5} \mathrm{M}\right)$ produced contraction in rabbit aorta strips. Responses to phenylephrine were reproducible, and time-dependent changes were not observed. Fentanyl $\left(10^{-9} \mathrm{M}-10^{-5} \mathrm{M}\right)$ administered to endothelium intact preparations at the plateau of a maximal contraction to phenylephrine $\left(10^{-5} \mathrm{M}\right)$, induced relaxation in a concentration-dependent manner (Figures 1 and 2). Removal of endothelium significantly reduced the relaxant response to fentanyl when compared with the endothelium intact rabbit aorta strips (Table 1). Preincubation of the rabbit aorta strips with L-NAME $\left(10^{-4} \mathrm{M}\right)$, significantly reduced the relaxant response to fentanyl when compared with the control group $(\mathrm{p}<0.05)$. Similarly, the relaxant responses of aorta strips to fentanyl were also inhibited significantly by glibenclamide $\left(10^{-5} \mathrm{M}\right)$, and ouabain $\left(10^{-5} \mathrm{M}\right)(\mathrm{p}<0.05)$ (Figure 1). Prein- cubation of the strips with naloxone $\left(10^{-5} \mathrm{M}\right)$, and with indomethacin $\left(10^{-5} \mathrm{M}\right)$ or preincubation with TEA $\left(10^{-4} \mathrm{M}\right)$ did not influence relaxant responses to fentanyl in intact rabbit aorta strips $(p>0.05)$ (Figure 2). The effects of endothelium removal and various pre-treatment agents used on the $\mathrm{E}_{\max }$ and $\mathrm{pIC}_{50}$ values for fentanyl are presented in Table 1. 


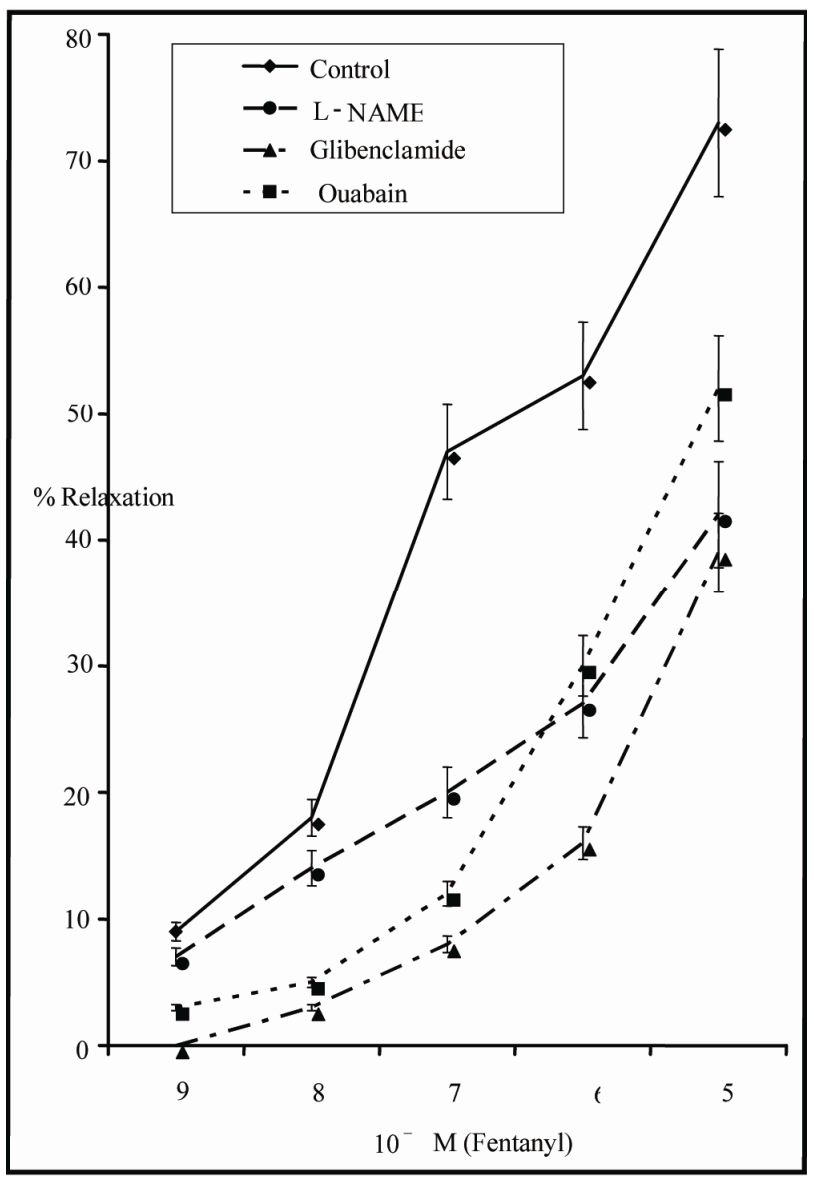

Figure 1. Concentration-response curves for fentanyl $\left(\mathbf{1 0}^{-9}\right.$ $-10^{-5} \mathrm{M}$ ) on phenylephrine-induced constriction of rabbit aorta strips after incubation with l-NAME $\left(10^{-4} \mathrm{M}\right)$, glibenclamide $\left(10^{-6} \mathrm{M}\right)$ and ouabain $\left(10^{-5} \mathrm{M}\right)$. Data expressed as the percentage of the control contractile response elicited at $10^{-5} \mathrm{M}$ of phenylephrine. mean $\pm \mathrm{SD}(\mathrm{n}=\mathbf{8}$ for each group).

Table 1. The $E_{\max }$ (the percentage of the maximal response of the tissue) and $\mathrm{pIC}_{50}$ (the negative logarithm of concentration eliciting $50 \%$ of the maximal relaxation) values for fentanyl $\left(10^{-9}-10^{-5} \mathrm{M}\right)$ induced relaxation in endothelium intact and endothelium denuded rabbit aorta strips and after various pre-treatment agents.

\begin{tabular}{ccc}
\hline & $\mathrm{E}_{\max }(\%)$ & $\mathrm{pIC}_{50}$ \\
Endothelium intact $(\mathrm{n}=8)$ & $72.8 \pm 5.2$ & $7.4 \pm 0.19$ \\
Endothelium denuded & $36.4 \pm 4.3^{*}$ & $5.9 \pm 0.12^{*}$ \\
$(\mathrm{n}=8)$ & $41.8 \pm 4.2^{*}$ & $6.8 \pm 0.11^{*}$ \\
L-NAME $\left(10^{-4} \mathrm{M}\right)(\mathrm{n}=8)$ & $7.6 \pm 0.13$ \\
$\begin{array}{c}\text { Indomethacin }\left(10^{-5} \mathrm{M}\right) \quad(\mathrm{n} \\
=8)\end{array}$ & $62.3 \pm 4.8$ & $7.2 \pm 0.17$ \\
TEA $\left(10^{-4} \mathrm{M}\right)(\mathrm{n}=8)$ & $65.4 \pm 5.3$ & $5.7 \pm 0.14^{*}$ \\
Glibenclamide $\left(10^{-6} \mathrm{M}\right)$ & $39.2 \pm 3.8^{*}$ & $6.2 \pm 0.13^{*}$ \\
$(\mathrm{n}=8)$ & $51.9 \pm 4.2^{*}$ & $7.3 \pm 0.15$ \\
Ouabain $\left(10^{-5} \mathrm{M}\right)(\mathrm{n}=8)$ & \\
Naloxone $\left(10^{-5} \mathrm{M}\right)(\mathrm{n}=8)$ & $70.2 \pm 5.1$ & \\
\hline
\end{tabular}

Statistical significance of $\mathrm{p}<0.05$, as compared with the control group.

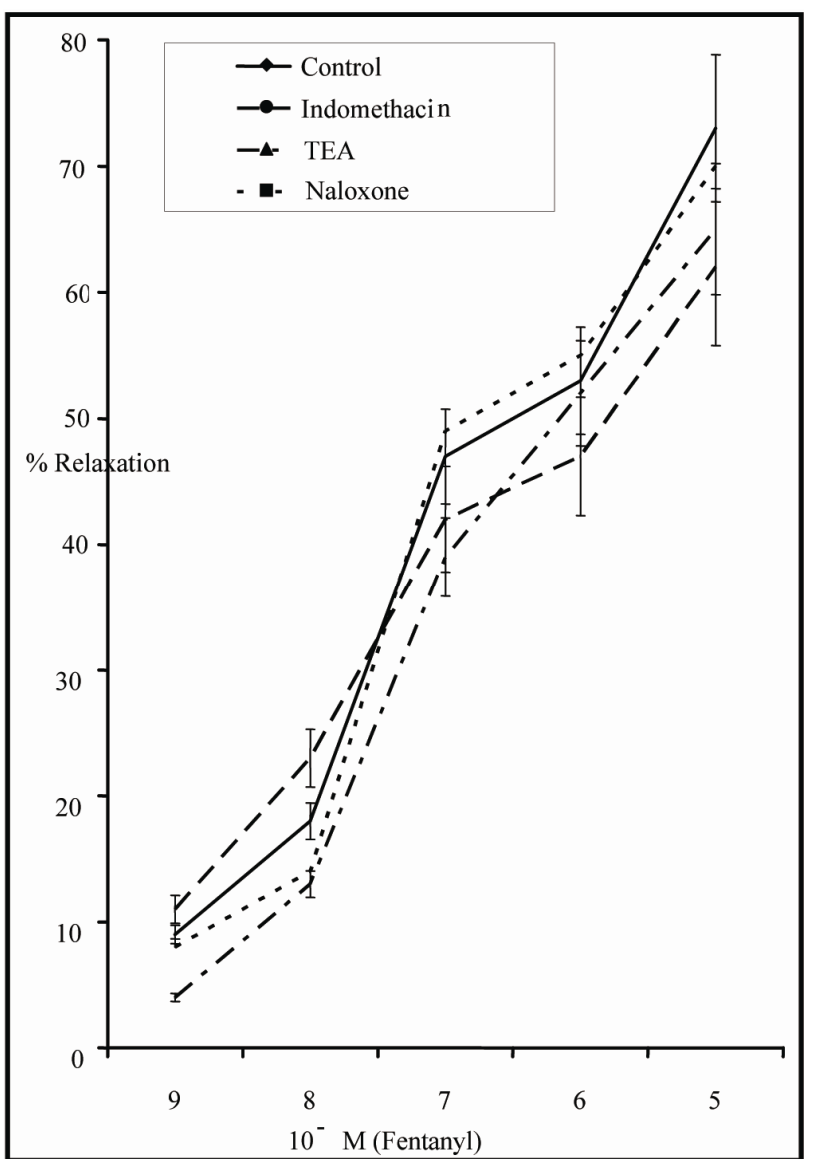

Figure 2. Concentration-response curves for fentanyl $\left(\mathbf{1 0}^{-9}\right.$ $\left.-10^{-5} \mathrm{M}\right)$ on phenylephrine-induced constriction of rabbit aorta strips after incubation with indomethacin $\left(10^{-5} \mathrm{M}\right)$, TEA $\left(10^{-4} \mathrm{M}\right)$ and naloxone $\left(10^{-5} \mathrm{M}\right)$. Data expressed as the percentage of the control contractile response elicited at $10^{-5} \mathrm{M}$ of phenylephrine. mean $\pm \mathrm{SD}$ ( $\mathrm{n}=\mathbf{8}$ for each group).

\section{Discussions}

Results of this in vitro study show that fentanyl causes concentration-dependent relaxation in rabbit aorta rings precontracted with phenylephrine. Removal of the endothelium does not totally block but significantly reduces the relaxant response to fentanyl. Nitric oxide synthase inhibitor L-NAME, $\mathrm{K}^{+}$channel blocker glibenclamide and $\mathrm{Na}^{+}-\mathrm{K}^{+}$-ATPase inhibitor ouabain inhibits the relaxant effect of fentanyl in endothelium intact aorta rings.

The present results imply that inhibitory effect of fentanyl on phenylephrine-induced contractions in rabbit aorta strips has both endothelium dependent and endothelium independent components. Endothelium releases autacoids such as NO and prostacyclin [8,9]. These autacoids could modulate the response of relaxant agents. In the present study, fentanyl-induced relaxation responses decreased significantly in the presence of L- 
NAME, which is an inhibitor of nitric oxide synthase enzyme. This finding suggests that NO released from endothelium may play a partial role in fentanyl-caused arterial dilation. On the other hand, the block of prostacyclin synthesis with indomethacin did not change these responses. These results suggest that the relaxant effects of fentanyl on rabbit aorta are partially mediated by endothelium derived NO rather than prostacyclin. Previous research on the effect of fentanyl on vascular reactivity on different species and vessels revealed different results. In studies conducted on human radial artery and porcine coronary artery, it was shown that the relaxant effect of fentanyl is independent of the endothelium $[3,10]$. Similarly, in another study conducted on human saphenous veins the vasorelaxant effect of fentanyl was not reversed by NO and prostacyclin synthase blockade [11].

Kaye et al. demonstrated that fentanyl has potent vasodepressor activity in the pulmonary vascular bed of the cat and this response may be mediated opiate receptor sensitive pathways [12]. To determine if vascular responses were mediated by an opioid receptor, dose-response studies for fentanyl were repeated in the presence of naloxone, an opioid-receptor antagonist. Similar to Sohn et al. [13] who studied the effects alfentanil, an opioid with a similar structure to fentanyl on phenylephrine-induced contractions in rat aorta, our results also show that, in the presence of naloxone, fentanyl's effect was unchanged, indicating that vasodilatation was not mediated by opioid receptors in rabbit aorta.

Potassium $\left(\mathrm{K}^{+}\right)$channels play an important role in the regulation of vascular smooth muscle cell membrane excitability and tonus [14]. The activation of $\mathrm{K}^{+}$channels in the vascular smooth muscles hyperpolarizes the cell membranes and closes voltage dependent $\mathrm{Ca}^{2+}$ channels. These actions decrease intracellular $\mathrm{Ca}^{2+}$ and cause vascular smooth muscle relaxation. On the contrary, the inhibition of the channels produces membrane depolarization and vascular smooth muscles contraction. In the present study, glibenclamide, ATP-sensitive $\mathrm{K}^{+}$channel blocker, and TEA, $\mathrm{Ca}^{2+}$-activated $\mathrm{K}^{+}$channel blocker, were used to characterize the mechanism of fentanylinduced relaxation in rabbit aorta. Relaxant activity of fentanyl in rabbit aorta was not blocked by TEA, but was antagonized by glibenclamide, reflecting some role of the hyperpolarizing ATP-sensitive K-channels in the mechanism of action of the drug. In their study on human saphenous veins, Sahin et al. found that the addition of glibenclamide (ATP sensitive $\mathrm{K}^{+}$canal blockers) and TEA $\left(\mathrm{K}^{+}\right.$canal blockers activated by $\left.\mathrm{Ca}^{++}\right)$suppress the fentanyl induced relaxation responses [12].

Previous studies suggest that the sarcolemmal $\mathrm{Na}^{+}-\mathrm{K}^{+}$ -ATPase plays an essential role in the maintenance of the vascular smooth muscle tone [15-17]. In smooth muscles, this pump can directly contribute to the cell resting membrane potential by actively pumping more sodium ions out than potassium ions into the cells [18]. Membrane depolarization in response to inhibition of $\mathrm{Na}^{+}-\mathrm{K}^{+}$ -ATPase caused $\mathrm{Ca}^{++}$channels to open and/or in- creased $\mathrm{Ca}^{2+}$ influx through $\mathrm{Na}^{+}-\mathrm{Ca}^{2+}$ exchange mecha- nism. It has been suggested that normal $\mathrm{Na}^{+}-\mathrm{K}^{+}$-ATPase activity is necessary for mediating vasorelaxant effects of some drugs $[19,20]$. In rabbit aorta strips, the relaxant effect of fentanyl was inhibited by ouabain. Such partial inhibition has also been obtained with ouabain in human saphenous vein [12].

Results of this study provides evidence that increasing doses of fentanyl result in concentration-dependent relaxation in the rabbit aorta. Both endothelium-dependent and endothelium-independent mechanisms are involved in the relaxation activation of $\mathrm{K}_{\text {ATP }}$ channels and $\mathrm{Na}^{+}-\mathrm{K}^{+}$ -ATPase, and nitric oxide released from the endothelium are responsible for the vasodilation caused by fentanyl. Further research will be needed to elucidate the exact pathways of fentanyl-induced vasoreactivity in blood vessels.

\section{References}

[1] G. Feuerstein and A. L. Siren, "The Opioid System in Cardiac and Vascular Regulation of Normal and Hypertensive States," Circulation, Vol. 75, No. 1, 1987, pp. 125129.

[2] G. A. Blaise, T. M. Witzeling, J. C. Sill, P. Vinay and P. M. Vanhoutte, "Fentanyl is Devoid of Major Effects on Coronary Vasoreactivity and Myocardial Metabolism in Experimental Animals," Anesthesiology, Vol. 72, No. 3, 1990, pp. 535-541.

doi:10.1097/00000542-199003000-00023

[3] A. P. Klockgether-Radke, J. Gravemann, D. Kettler and G. Hellige, "Influence of Opioids on Vascular Tone of Isolated Porcine Coronary Artery Segments," Acta Anaesthesiologica Scandinavica, Vol. 44, No. 9, 2001, pp. 134-137. doi:10.1034/j.1399-6576.2000.440917.x

[4] R. P. S. Introna, M. T. Bridges, E. H. Yoldlowski, T. E. Graver and J. K. Pruett, "Direct Effects of Fentanyl on Canine Coronary Artery Rings," Life Sciences, Vol. 56, No. 15, 1995, pp. 1265-1273. doi:10.1016/0024-3205(95)00072-0

[5] F. Karasawa, V. Iwanov and R. F. Moulds, "Effects of Fentanyl on the Rat Aorta are Mediated by AlphaAdrenoceptors rather than by the Endothelium," British Journal of Anaesthesia, Vol. 71, No. 6, 1993, pp. 877-880. doi:10.1093/bja/71.6.877

[6] K. E. Park, J. T. Sohn, Y. S. Jeong, H. J. Sung, I. W. Shin, H. K. Lee and Y. K. Chung, "Inhibitory Effect of Fentanyl on Phenylephrine-Induced Contraction of the Rat Aorta," Yonsei Medical Journal, Vol. 50, No. 3, 2009, pp. 414-421. doi:10.3349/ymj.2009.50.3.414

[7] D. A. White, J. A. Reitan, N. D. Kein and S. J. Thorup, 
"Decrease in Vascular Resistance in the Isolated Canine Hindlimb after Graded Doses of Alfentanil, Fentanyl, and Sufentanil," Anesthesia Analgesia, Vol. 71, No. 1, 1990, pp. 29-34. doi:10.1213/00000539-199007000-00005

[8] R. F. Furchgott and J. V. Zawadzki, "The Obligatory Role of Endothelial Cells in the Relaxation of Arterial Smooth Muscle by Acetylcholine," Nature, Vol. 288, No. 5789, 1980, pp. 373-376. doi:10.1038/288373a0

[9] G. M. Rubanyi, "The Discovery of Endothelin: The Power of Bioassay and the Role of Serendipity in the Discovery of Endothelium-Derived Vasocative Substances," Pharmacological Research, Vol. 8, 2010, (Ahead of Print).

[10] S. Gursoy, I. Bagcivan, M. K. Yildirim, O. Berkan and T. Kaya, "Vasorelaxant Effect of Opioid Analgesics on the Isolated Human Radial Artery," European Journal of Anaesthesiology, Vol. 23, No. 6, 2006, pp. 496-500. doi:10.1017/S0265021506000172

[11] S. Moncada and J. R. Vane, "Pharmacology and Endogenous Roles of Prostaglandin Endoperoxides, Thromboxane A2, and Prostacyclin," Pharmacological Reviews, Vol. 30, No. 3, 1978, pp. 293-320.

[12] A. S. Sahin, A. Duman, E. K. Atalı, C. O. Ogun, T. K. Şahin, A. Erol and U. Ozergin, "The Mechanisms of the Direct Vascular Effects of Fentanyl on Isolated Human Saphenous Veins in Vitro," Journal of Cardiothoracic and Vascular Anesthesia, Vol. 19, No. 2, 2005, pp. 197200. doi:10.1053/j.jvca.2005.01.031

[13] J. T. Sohn, K. E. Park, C. Kim, Y. S. Jeong, I. W. Shin, H. K. Lee and Y. K. Chung, "Alfentanil Attenuates Phenylephrine Induced Contraction in Rat Aorta," European Journal of Anaesthesiology, Vol. 24, No. 3, 2007, pp. 276-282. doi:10.1017/S0265021506001621

[14] A. D. Kaye, J. M. Hoover, I. N. Ibrahim, J. Phelps, A. Baluch, A. Fields and S. Huffman, "Analysis of the Effects of Fentanyl in the Feline Pulmonary Vascular Bed,"
American Journal of Therapeutics, Vol. 13, No. 6, 2006, pp. 478-484.

[15] M. Hirafuji, F. Kawahara, T. Ebihara, A. Nezu, A. Tanimura and M. Minami, "5-Hydroxytryptamine Induces Transient $\mathrm{Ca}^{2+}$ Influx Through $\mathrm{Ni}^{2+}$ - Insentive $\mathrm{Ca}^{2+}$ Channels in Rat Vascular Smooth Muscle Cells," European Journal of Pharmacology, Vol. 380, No. 2-3, 1999, pp. 163-170.

[16] J. Daut, N. B. Standen and M. T. Nelson, "The Role of the Membrane Potential of Endothelial and Smooth Muscle Cells in the Regulation of Coronary Blood Flow," Journal of Cardiovascular Electrophysiology, Vol. 5, No. 2, 1994, pp. 154-181. doi:10.1111/j.1540-8167.1994.tb01156.x

[17] J. Marin, C. F. Sanchez-Ferrer and M. Salaices, "Effects of Ouabain on Isolated Cerebral and Femoral Arteries of the Cat: A Functional and Biochemical Study," British Journal of Pharmacology, Vol. 93, No. 1, 1988, pp. 43-52.

[18] M. S. Fernandez-Alfonso, C. F. Sanchez-Ferrer, M. C. Hernandez and J. Marin, " $\mathrm{Na}^{+} / \mathrm{Ca}^{2+}$ Exchange Mediation in the Ouabain-Induced Contraction in Human Placental Vessels," General Pharmacology, Vol. 23, No. 3, 1992, pp. 439-444. doi:10.1016/0306-3623(92)90109-W

[19] C. Barajas-Lopez and J. D. Huizinga, "Ouabain-Induced Excitation of Colonic Smooth Muscle due to Block of $\mathrm{K}^{+}$ Conductance by Intracellular $\mathrm{Na}^{+}$Ions," European Journal of Pharmacology, Vol. 221, No. 1, 1992, pp. 75-82. doi:10.1016/0014-2999(92)90771-U

[20] R. Shibata, S. Morita, K. Nagai, S. Miyata and T. Iwasaki, "Calcium Dependence of Ouabain-Induced Contraction in Aortas from Spontaneously Hypertensive Rats," European Journal of Pharmacology, Vol. 190, No. 1-2, 1990, pp. 147-157. doi:10.1016/0014-2999(90)94121-D 